Pacific Journal of Mathematics

A SPHERE CHARACTERIZATION RELATED TO BLASCHKE'S
CONJECTURE

LeN W. GRe 


\title{
A SPHERE CHARACTERIZATION RELATED TO BLASCHKE'S CONJECTURE
}

\author{
LEON W. GREEN
}

Let $S$ be a $C^{3}$-surface supplied with a complete positive-definite Riemannian metric. If $R=R(s)$ is a geodesic ray with initial element (point and direction) $e=(P, \theta)$ and arc-length $s$, and $h=(P, \theta \pm \pi / 2)$ is an orthogonal element at $P$, we call $F(e)$ the focal distance for $e$ if $R(F(e))$ is the first focal point along $R$ to the element $h$. (This definition will be given an analytic form in $\S 1$.)

THEOREM 1. If $F(e)$ is finite and independent of the initial element $e$ in the unit tangent bundle of $S$, then $S$ has constant positive curvature.

The hypothesis implies that $2 F(e)$ is the distance to the first point conjugate to $P$ along $R$; hence this conjugate distance is constant. A longstanding conjecture of Blaschke's is: if the conjugate distance on $S$ is finite and independent of the initial element, the surface has constant positive curvature. If one accepts as true a sentence (Blaschke [2], top of page 228) in his critique of Reidemeister's erroneous proof ([1], Anhang) of the conjecture, it is sufficient to prove the theorem as we state it for focal points. However, we have not been able to prove the assertion contained in that sentence.

Busemann ([3], Theorem 21.10) has proved an analogue of our theorem for $G$-spaces of dimension greater than two, so the generalization to Riemannian manifolds of higher dimension is contained in his result. For two-dimensional $G$-spaces even of class $C^{\infty}$, Blaschke's conjecture is false, as examples of Hamel show [4].

In $\S 1$ we give the analytic setting of the problem and summarize the pertinent known facts. $\$ 2$ contains a result in ordinary differential equations which implies the main theorem.

1. Express the line element of $S$ in geodesic polar coordinates with center $P$ :

$$
d s^{2}=d r^{2}+G^{2} d \theta^{2} .
$$

Then it is known that $G=G(r, \theta)$ satisfies the Jacobi differential equation

$$
\begin{aligned}
G_{r r}(r, \theta)+K(r, \theta) G(r, \theta) & =0, \\
G(0, \theta)=0, \quad G_{r}(0, \theta) & =1,
\end{aligned}
$$

Received July 17, 1959. Presented to the AMS, January 22, 1959, under the title "On a problem of Blaschke's". Research supported by NSF contract G-5256. 
where $K(r, \theta)$ is the Gaussian curvature of $S$ at a distance $r$ from the point $P$ along the geodesic ray with initial element $(P, \theta)$. Along any such ray the line element is positive definite for $0<r<C(\theta)$, where $C(\theta)$ is the first positive value of $r$ for which $G(r, \theta)=0$. The point $(C(\theta), \theta)$ is the first point conjugate to $P$ along the ray $R(s)=(s, \theta)$. The mapping from the $(r, \theta)$ plane to $S$ is locally one-to-one along any geodesic ray $(s, \theta)$ of length less than $C(P, \theta)$. The first point focal to $P$ along $(s, \theta)$ is defined to be the point $(F(\theta), \theta)$, where $F(\theta)$ is the first zero of $G_{r}(r, \theta)$ for increasing $r$, Geometrically, it is the first point along a ray at which the geodesic circle of that radius ceases to be (locally) strictly convex. Thus we may drop the transversality parts of the usual calculus of variations definition, provided we understand that "focal" in our sense has a restricted meaning.

For the remainder of this section we shall assume that $C(P, \theta)$ is finite and independent of $P$ and $\theta$ on $S$. Without loss of generality we may assume that this constant is $\pi$. Much of Blaschke's discussion ([2], $\S 102)$ holds, and the following paragraph will be a summary without proof of the verifiable statements which he makes that we will need.

All geodesics of $S$ are closed. Any two geodesics which pass through the point $P$ intersect at a point $P^{\prime}$, the common point conjugate to $P$ along all rays through $P . S$ is covered by a homeomorph of the twosphere with the same conjugate point distance. From now on we assume $S$ simply-connected and call the distinct and unique point $P^{\prime}$ the antipode of $P$. The distance from $P$ to $P^{\prime}$ along any ray is $\pi$; the length of every closed geodesic is $2 \pi$. The mapping of points into their antipodes is an isometric involution of $S$ onto itself. (Most of these facts are also proved for $G$-spaces in Busemann [3].)

It follows that the line element (L) with any center $P$ is definite for $0<r<\pi$. Since the Gaussian curvature is a scalar function on the surface, we may consider $(\mathrm{J})$ along a fixed closed geodesic as an ordinary differential equation with periodic coefficients. Choosing a different origin on the same geodesic and solving $(J)$ yields a solution in the original coordinates with initial values prescribed at some point other than $r=$ 0 . Any solution $u(r)$ of $(\mathrm{J})$ which vanishes at $r_{0}$ also vanishes at $r_{0}=$ $n \pi$. Since the antipodal map is an isometry, $K(r, \theta)=K(r \pm \pi, \theta)$ and the function $G$ in (L) satisfies $G(r-\pi, \theta+\pi)=G(r, \theta)$ for $0 \leq r \leq \pi$. Because of the uniqueness of the solutions under the imposed boundary conditions, if we consider a solution $u(r)$ of $(\mathrm{J})$ with the same initial conditions as defined for all $r, u(r)=-u(r-\pi)$. Consequently every solution of $(\mathrm{J})$ is odd-harmonic and periodic of period $2 \pi$.

If we adjoin the condition that $F(e)$ is constant (and equals $\pi / 2$ ), then every solution of $(J)$ which vanishes at $r_{0}$ has zero first derivative at $r_{0}+\pi / 2$. 
2. The analytic situation which we shall exploit may now be summarized as follows:

(H) Every solution of the differential equation

$$
y^{\prime \prime}(r)+K(r) y(r)=0
$$

is odd-harmonic (i.e., $y(r-\pi)=-y(r)$ ), periodic of period $2 \pi$, and if $y\left(r_{0}\right)=0$, then $y^{\prime}\left(r_{0}+\pi / 2\right)=0$ (focal point condition). Here $K(r)$ is continuous and of period $\pi$.

In this section $w(r, a)$ will always designate a solution of $\left(\mathrm{J}^{\prime}\right)$ satisfying $w(a, a)=0, w_{r}(a, a)=1$. We set $u(r)=w(r, 0)$ and let $v(r)$ be that solution of $\left(\mathrm{J}^{\prime}\right)$ with the initial conditions $v(0)=1, v^{\prime}(0)=0$.

LEMma. Under the assumptions $(H), w(a+\pi / 2, a)$ is independent of $a$.

Proof. In terms of the independent basis of solutions we may write

$$
w(r, a)=v(a) u(r)-u(a) v(r) .
$$

Then the focal point condition becomes

$$
v(a) u^{\prime}(a+\pi / 2)=u(a) v^{\prime}(a+\pi / 2)
$$

for every $a$. Putting $b=a+\pi / 2$ and using the odd-harmonicity,

$$
v(b+\pi / 2) u^{\prime}(b)=u(b+\pi / 2) v^{\prime}(b)
$$

for every $b$. Now differentiate (1) with respect to $a$ :

$$
w_{a}(r, a)=v^{\prime}(a) u(r)-u^{\prime}(a) v(r) .
$$

Using (3), we see that $w_{a}(a+\pi / 2, a)=0$. Combining this with the hypothesis on the derivative with respect to the first variable, we conclude that the total derivative with respect to $a$ of $w(a+\pi / 2, a)$ is zero for all $a$. This proves the lemma.

Theorem 2. Under the hypotheses $(H), K(r)$ is identically 1.

Proof. At any point $a$ where $u^{\prime}(a+\pi / 2) \neq 0$ we may solve (2) for $v(a)$ and substitute in (1) to find the constant value of $w(a+\pi / 2, a)$ :

$$
\begin{aligned}
u(\pi / 2)= & w(\pi / 2,0)=w(a+\pi / 2, a) \\
= & {\left[u^{\prime}(a+\pi / 2)\right]^{-1}\left[u(a) v^{\prime}(a+\pi / 2) u(a+\pi / 2)\right.} \\
& \left.-u(a) v(a+\pi / 2) u^{\prime}(a+\pi / 2)\right] \\
= & -u(a) / u^{\prime}(a+\pi / 2),
\end{aligned}
$$


using the fact that the Wronskian is constant. In particular, at every such point $a, u(a) \neq 0$ also. Hence we may divide (2) further to find that, for all intervals in which $u^{\prime}(a+\pi / 2) \neq 0$,

$$
v(a) / u(a)=v^{\prime}(a+\pi / 2) / u^{\prime}(a+\pi / 2) .
$$

Differentiating and substituting from $\left(\mathrm{J}^{\prime}\right)$ :

$$
\begin{aligned}
& {\left[u(a) v^{\prime}(a)-v(a) u^{\prime}(a)\right] /[u(a)]^{2} } \\
= & \frac{u^{\prime}(a+\pi / 2) v^{\prime \prime}(a+\pi / 2)-v^{\prime}(a+\pi / 2) u^{\prime \prime}(a+\pi / 2)}{\left[u^{\prime}(a+\pi / 2)\right]^{2}} \\
= & \frac{K(a+\pi / 2)\left[v^{\prime}(a+\pi / 2) u(a+\pi / 2)-u^{\prime}(a+\pi / 2) v(a+\pi / 2)\right]}{\left[u^{\prime}(a+\pi / 2)\right]^{2}} .
\end{aligned}
$$

Another recognition of the Wronskian allows us to conclude that

$$
K(a+\pi / 2)=\left[\frac{u^{\prime}(a+\pi / 2)}{u(a)}\right]^{2}=[u(\pi / 2)]^{-2},
$$

a constant independent of $a$. The fact that the zeroes of $u^{\prime}(r)$ are isolated together with the continuity of $K$ completes the argument that $K$ is constant everywhere. (Or one may notice that the choice of origin was arbitrary.) Since the period of the solutions is $2 \pi$, the value of $K$ is determined. This completes the proof of Theorem 2, and clearly implies the truth of Theorem 1.

3. Warren Loud has indicated to me how to obtain non-constant periodic functions $K(r)$ such that all solutions of $\left(\mathrm{J}^{\prime}\right)$ are periodic and odd-harmonic (cf. his monograph [6], §3). Hence the method given here cannot be directly extended to prove Blaschke's conjecture. (Perhaps this remark should be added to Blaschke's “Warnungstafel".)

If one considers the equation $(J)$ as a one-parameter family of ordinary differential equations and uses the hypothesis that the spectral value 0 does not change under perturbation, one obtains (in the analytic case) an infinite sequence of conditions on the derivatives of $K(r, \theta)$, of which that given by Blaschke ([2], page 226) is only the first.

By using classical Sturm-Liouville techniques, one can also prove

THEOREM 3. Let $K(r, \theta)$ be analytic for $|\theta|<\theta_{0}$, and such that $K(r, \theta) \rightarrow \infty$ uniformly in some interval of $r$ as $\theta \rightarrow \theta_{0}$. Then it cannot happen that every solution of $(J)$ is periodic with period independent of $\theta$.

We omit the proof. (It is essentially given, e.g., in Haupt [5].) If it were not for the growth hypothesis, which doesn't correspond to the geometrical situation, this would imply the truth of Blaschke's conjecture, since any two points on $S$ lie on a geodesic circle. 


\section{REFERENCES}

1. W. Blaschke, Vorlesungen über Differentialgeometrie, $2^{\text {te }}$ Auflage, Berlin, 1924

2. Ibid., $3^{\text {te }}$ Auflage, 1930.

3. H. Busemann, The Geometry of Geodesics, New York, 1955.

4. G. Hamel, Uber die Geometrien, in denen die Geraden die Kürzesten sind; Math. Annalen 57 (1903), 221-264.

5. O. Haupt, Uber lineare homogene Differentialgleichungen 2. Crdnung mit periodischen Koeffizienten, Math. Annalen 79 (1919), 278-285.

6. W. Loud, Periodic solutions of $x^{\prime \prime}+c x^{\prime}+g(x)=\varepsilon f(t)$, Memoirs of the Amer. Math. Soc., 311959.

UNIVERSITY OF MINNESOTA 



\section{PACIFIC JOURNAL OF MATHEMATICS}

\section{EDITORS}

\author{
David Gilbarg \\ Stanford University \\ Stanford, California \\ F. H. Brownell \\ University of Washington \\ Seattle 5 , Washington
}

\author{
A. L. Whiteman \\ University of Southern California \\ Los Angeles 7, California \\ L. J. PAIGE \\ University of California \\ Los Angeles 24, California
}

\section{ASSOCIATE EDITORS}

\author{
E. F. BECKENBACH \\ T. M. CHERRY \\ D. DERRY
}
E. HEWITT
A. HORN
L. NACHBIN
M. OHTSUKA
H. L. ROYDEN
M. M. SCHIFFER

E. SPANIER

E. G. STRAUS

F. WOLF

\section{SUPPORTING INSTITUTIONS}

\author{
UNIVERSITY OF BRITISH COLUMBIA \\ CALIFORNIA INSTITUTE OF TECHNOLOGY \\ UNIVERSITY OF CALIFORNIA \\ MONTANA STATE UNIVERSITY \\ UNIVERSITY OF NEVADA \\ NEW MEXICO STATE UNIVERSITY \\ OREGON STATE COLLEGE \\ UNIVERSITY OF OREGON \\ OSAKA UNIVERSITY \\ UNIVERSITY OF SOUTHERN CALIFORNIA
}

\author{
STANFORD UNIVERSITY \\ UNIVERSITY OF TOKYO \\ UNIVERSITY OF UTAH \\ WASHINGTON STATE COLLEGE \\ UNIVERSITY OF WASHINGTON

AMERICAN MATHEMATICAL SOCIETY
CALIFORNIA RESEARCH CORPORATION
HUGHES AIRCRAFT COMPANY
SPACE TECHNOLOGY LABORATORIES
NAVAL ORDNANCE TEST STATION

Mathematical papers intended for publication in the Pacific Journal of Mathematics should be typewritten (double spaced), and the author should keep a complete copy. Manuscripts may be sent to any one of the four editors. All other communications to the editors should be addressed to the managing editor, L. J. Paige at the University of California, Los Angeles 24, California. ..

50 reprints per author of each article are furnished free of charge; additional copies may be obtained at cost in multiples of 50 .

The Pacific Journal of Mathematics is published quarterly, in March, June, September, and December. The price per volume (4 numbers) is $\$ 12.00$; single issues, $\$ 3.50$. Back numbers are available. Special price to individual faculty members of supporting institutions and to individual members of the American Mathematical Society: $\$ 4.00$ per volume; single issues, $\$ 1.25$.

Subscriptions, orders for back numbers, and changes of address should be sent to Pacific Journal of Mathematics, 2120 Oxford Street, Berkeley 4, California.

Printed at Kokusai Bunken Insatsusha (International Academic Printing Co., Ltd.), No. $6_{4}$ 2-chome, Fujimi-cho, Chiyoda-ku, Tokyo, Japan.

PUBLISHED BY PACIFIC JOURNAL OF MATHEMATICS, A NON-PROFIT CORPORATION

The Supporting Institutions listed above contribute to the cost of publication of this Journăl, but they are not owners or publishers and have no responsibility for its content or policies. 


\section{Pacific Journal of Mathematics}

\section{Vol. 10, No. $3 \quad$ November, 1960}

Glen Earl Baxter, An analytic problem whose solution follows from a simple

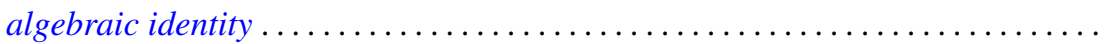

Leonard D. Berkovitz and Melvin Dresher, A multimove infinite game with linear payoff. .

Earl Robert Berkson, Sequel to a paper of A. E. Taylor ......................

Gerald Berman and Robert Jerome Silverman, Embedding of algebraic systems.... 767

Peter Crawley, Lattices whose congruences form a boolean algebra . . . . . ...... 777

Robert E. Edwards, Integral bases in inductive limit spaces . . . . . . . . . . . . . . .

Daniel T. Finkbeiner, II, Irreducible congruence relations on lattices . . . . . . . . . .

William James Firey, Isoperimetric ratios of Reuleaux polygons . . . . . . . . . . . 787

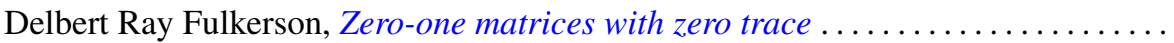

Leon W. Green, A sphere characterization related to Blaschke's conjecture........

Israel (Yitzchak) Nathan Herstein and Erwin Kleinfeld, Lie mappings in

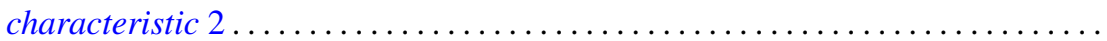

Charles Ray Hobby, A characteristic subgroup of a $p$-group .................

R. K. Juberg, On the Dirichlet problem for certain higher order parabolic

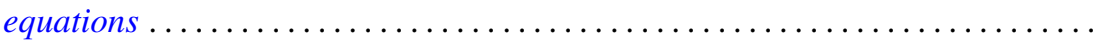

Melvin Katz, Infinitely repeatable games ......................

Emma Lehmer, On Jacobi functions . . . . . . . . . . . . . . . . . . . . . . . . .

D. H. Lehmer, Power character matrices

Henry B. Mann, A refinement of the fundamental theorem on the density of the sum of two sets of integers.

Marvin David Marcus and Roy Westwick, Linear maps on skew symmetric matrices: the invariance of elementary symmetric functions . .

Richard Dean Mayer and Richard Scott Pierce, Boolean algebras with ordered

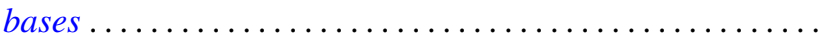

Trevor James McMinn, On the line segments of a convex surface in $E_{3} \ldots$

Frank Albert Raymond, The end point compactification of manifolds ..

Edgar Reich and S. E. Warschawski, On canonical conformal maps of regions of arbitrary connectivity

Marvin Rosenblum, The absolute continuity of Toeplitz's matrices...

Lee Albert Rubel, Maximal means and Tauberian theorems . .

Helmut Heinrich Schaefer, Some spectral properties of positive linear operators

Jeremiah Milton Stark, Minimum problems in the theory of pseudo-conformal transformations and their application to estimation of the curvature of the invariant metric.

Robert Steinberg, The simplicity of certain groups ...

Hisahiro Tamano, On paracompactness. .

Angus E. Taylor, Mittag-Leffler expansions and spectral theory .

Marion Franklin Tinsley, Permanents of cyclic matrices ...... . 